\title{
Tatuidris kapasi sp. nov.: A New Armadillo Ant from French Guiana (Formicidae: Agroecomyrmecinae)
}

\author{
Sébastien Lacau, ${ }^{1,2,3}$ Sarah Groc, ${ }^{4}$ Alain Dejean, ${ }^{4,5}$ \\ Muriel L. de Oliveira, ${ }^{1,3,6}$ and Jacques H. C. Delabie ${ }^{3,6}$ \\ ${ }^{1}$ Laboratório de Biossistemática Animal, Universidade Estadual do Sudoeste da Bahia, UESB/DEBI, 45700-000 Itapetinga, BA, Brazil \\ ${ }^{2}$ Département Systématique \& Evolution, UMR 5202 CNRS-MNHN, Muséum National d'Histoire Naturelle, 75005 Paris, France \\ ${ }^{3}$ Programa de Pós-Graduação em Zoologia, Universidade Estadual de Santa Cruz, UESC/DCB, 45662-000 Ilhéus, BA, Brazil \\ ${ }^{4}$ Écologie des Forêts de Guyane, UMR-CNRS 8172 (UMR EcoFoG), Campus Agronomique, BP 319, \\ 97379 Kourou Cedex, French Guiana \\ ${ }^{5}$ Université de Toulouse, UPS (Ecolab), 118 Route de Narbonne, 31062 Toulouse Cedex 9, France \\ ${ }^{6}$ Laboratório de Mirmecologia, CEPLAC/CEPEC/SECEN, CP 07, km 22, Rodovia, Ilhéus-Itabuna, 45600-970 Itabuna, BA, Brazil
}

Correspondence should be addressed to Sébastien Lacau, slacau@cepec.gov.br

Received 11 September 2011; Revised 3 November 2011; Accepted 21 November 2011

Academic Editor: Fernando Fernández

Copyright ( $) 2012$ Sébastien Lacau et al. This is an open access article distributed under the Creative Commons Attribution License, which permits unrestricted use, distribution, and reproduction in any medium, provided the original work is properly cited.

Tatuidris kapasi sp. nov. (Formicidae: Agroecomyrmecinae), the second known species of "armadillo ant", is described after a remarkable specimen collected in French Guiana. This species can be easily distinguished from Tatuidris tatusia by characters related to the shape of the mesosoma and petiole as well as to the pilosity, the sculpture, and the color.

\section{Introduction}

As a result of the constant acquisition of new morphological and molecular data, combined with a big increase in the collection of biological material, the last decades have seen a true revolution in ant systematics and phylogeny $[1,2]$. In spite of this, some rare genera of ants still remain unusually mysterious. A long time after their original description, they continue to reveal a low taxonomical diversity and are rarely collected in the field. Frequently, their phylogenetic relationships also remain poorly understood. The Neotropical genus Tatuidris (Formicidae: Agroecomyrmecinae) was described by Brown and Kempf in the 1967 issue of Psyche [3] after a peculiar new species collected in El Salvador. Until now, this genus has remained monotypic and very isolated in the Family Formicidae. The type species, Tatuidris tatusia, is known only from the very distinctive morphology of the worker that combines some primitive and derived characters, while its biology is completely unknown [4]. In addition, morphological and molecular studies have caused some authors to hold differing points of view regarding the phylogenetic position of Tatuidris in the family Formicidae. Thus, based on its morphology, the genus was initially placed in the subfamily Myrmicinae [3], within the tribe Agroecomyrmecini. The genus was then transferred to the Agroecomyrmecinae [5], a new subfamily proposed by Bolton, who has suggested that this taxon might be the sister group to all Myrmicinae. More recently, the genus was again combined in the Myrmicinae [6] and then returned to the Agroecomyrmecinae as a poneroid [7] and more latterly as a poneromorph [8]. However, based on morphological characters, in a very recent paper, Keller [9] corroborated Bolton's former proposal [5] in considering that Tatuidris is the sister group to the Myrmicinae. Recently, some new molecular data have led other authors to argument that Tatuidris may be the sister group to the subfamily Paraponerinae in some rooted trees but placed it next to Amblyoponinae in some other analyses [10-12].

In such a context, the search for new species of Tatuidris and the study of their morphology represents an important challenge for better understanding the phylogenetic relationships of this genus within the Formicidae. Here we report the recent finding in French Guiana of a remarkable single 
specimen of Tatuidris that differs from T. tatusia in several distinctive morphological characters, and this paper aims to describe it.

\section{Material and Methods}

Morphological examination of specimens was completed at various magnifications using a light stereomicroscope Olympus SZX7. Morphometric measures were made with a Carl Zeiss measuring microscope and recorded to the nearest $0.01 \mathrm{~mm}$. All measurements are given in millimeters, using the following definitions and abbreviations:

CI: Cephalic Index: HW $* 100 / \mathrm{HL}$,

EL: Eye Length: the maximum diameter of the eye,

GL: Gaster length: the length of the gaster in lateral view from the anteriormost point of first gastral segment (fourth abdominal segment) to the posterior most point (sting omitted),

HFL: Hind Femur Length: maximum length of hind femur in anterior view,

HL: Head Length: the length of the head proper, excluding the mandibles; measured in full-face view from the midpoint of the anterior clypeal margin to a line drawn across the posterior margin from its highest points,

HW: Head Width: the maximum width of the head in full face view,

LA7: Length of Antennal segment 7: maximum length of the seventh (apical) antennal segment,

ML: Mandible Length: length of a mandible measured in ventral view from its basal articulation to its apex,

PeNI: Petiole Node Index: (PeNW $* 100 / \mathrm{PeNL})$,

PeL: Petiole Length: the maximum length of the petiole in lateral view,

PeNL: Petiolar Node Length: the maximum length of the petiole node in dorsal view,

PeNW: Petiolar Node Width: the maximum width of the petiole node in dorsal view,

PpL: Postpetiole Length: the maximum postpetiole length in lateral view,

PpNL: Postpetiolar Node Length: the maximum length of the postpetiole node in dorsal view,

PpNW: Postpetiolar Node Width: the maximum width of the postpetiole node in dorsal view,

PrW: Pronotum Width: the maximum width of the pronotum in dorsal view,

PrpW: Propodeum Width: the maximum width between the propodeum angles as seen in dorsal view,

SL: Scape Length: the maximum straight line of the antennal scape, excluding the condylar bulb,

TL: Total Length $(\mathrm{HL}+\mathrm{ML}+\mathrm{WL}+\mathrm{PL}+\mathrm{PPL}+\mathrm{GL})$,
WL: Weber's Length: diagonal length, measured in lateral view, from the anterior margin of the pronotum (excluding the collar) to the posterior extremity of the metapleural lobe.

The microphotographs were made using the following sequential process: the specimen was first filmed using a video camera (Sony Full HD 1080 AVCHD, 10.2 Mp) mounted on a light microscope (Zeiss Jena), while the resolution was continuously scanned from the top to the bottom of the holotype specimen; the videos (in format.mts) were processed using the free software ImagGrab 5.0 (available at http://paul.glagla.free.fr/imagegrab.htm) in order to extract the sharpest images referable to differing focal points, and composite pictures were then assembled using the free software Combine ZM (available at http://www.hadleyweb .pwp.blueyonder.co.uk/index.htm). Finally, each optimum microphotograph was improved using Adobe Element Photoshop software (version 6.0).

The terminology for the external morphology and the surface sculpturing follows [13-15]. In the description and the diagnosis of this new species, our terminology referring to the pilosity describes the variation in size of the setae observed in T. tatusia and Tatuidris kapasi sp. nov. Thus, we recognize four setal types depending on their length: that is, very short (about $0.016 \mathrm{~mm}$ ), short (about $0.05 \mathrm{~mm}$ ), intermediate (about $0.11 \mathrm{~mm}$ ), and long (about $0.3 \mathrm{~mm}$ ). Also, the characters of the tribe and the genus are not mentioned (for a complete summary of the taxonomic characters, see $[3,5])$.

Depository of the Holotype. The unique known specimen of the taxon is deposited in the collection of the Laboratorio de Mirmecologia at the Cocoa Research Center at CEPLAC (Itabuna-BA, Brazil), referred to by the CPDC acronym [16]. Comparative data for Tatuidris tatusia were obtained from the literature [3] and direct observations on microphotographs of high-resolution available in AntWeb site [17].

\section{Results}

3.1. Tatuidris kapasi Lacau and Groc: New Species. See Figures 1, 2, 3, 4, 5, and 6.

3.2. Type Material. Holotype worker: specimen deposited at CPDC and labeled "Guyane Française, Montagne de Kaw, N04 ${ }^{\circ} 38.21^{\prime} / \mathrm{W} 052^{\circ} 17.36^{\prime}$, Alt. 260 m., ix.2008, Winkler trap, Col. S. Groc, A. Dejean, and B. Corbara".

3.3. Etymology. "kapasi" is the Wayanas' Amerindian (French Guiana, Surinam, and Brazil) word for "armadillo", a mammal belonging to the Order Cingulata. The generic and specific names of the first described species [6] referred to the same animal group.

3.4. Diagnosis. The worker of Tatuidris kapasi exhibits all the diagnostic characters of the tribe Agroecomyrmecini and the genus Tatuidris. It differs from the worker of T. tatusia in 


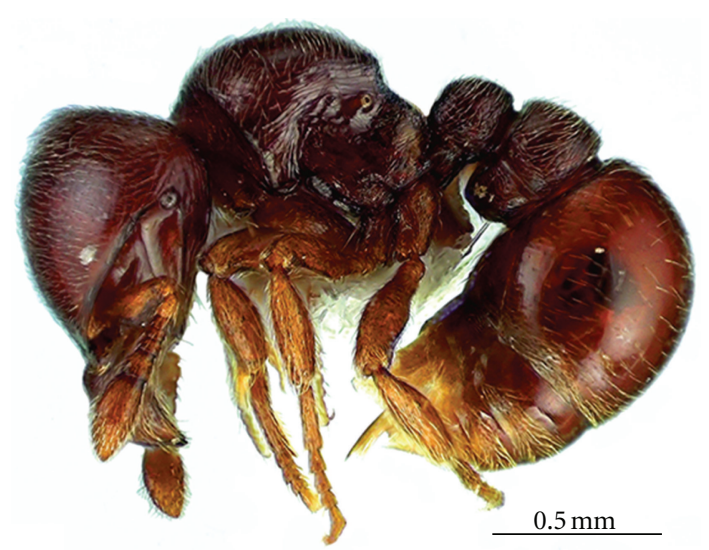

FIgure 1: Tatuidris kapasi: holotype worker. Habitus: left lateral view.

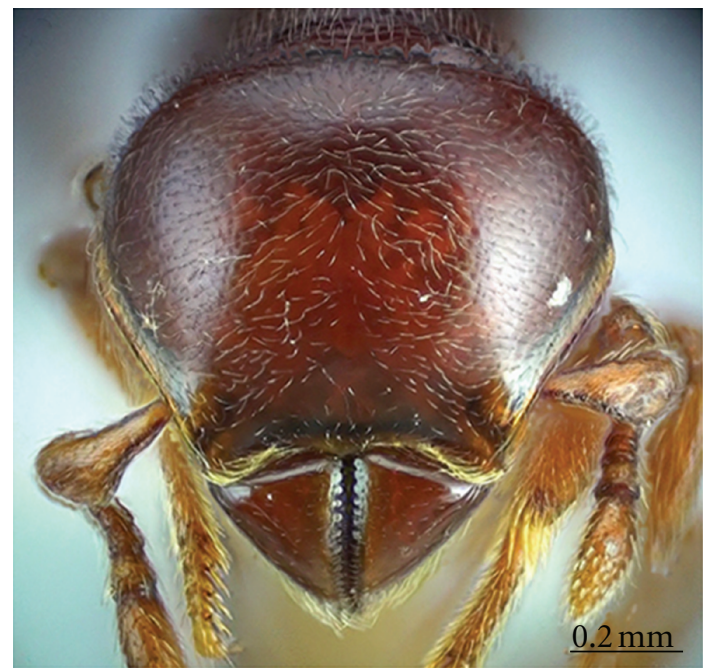

FIgure 2: Tatuidris kapasi: holotype worker. Head: full-face view.

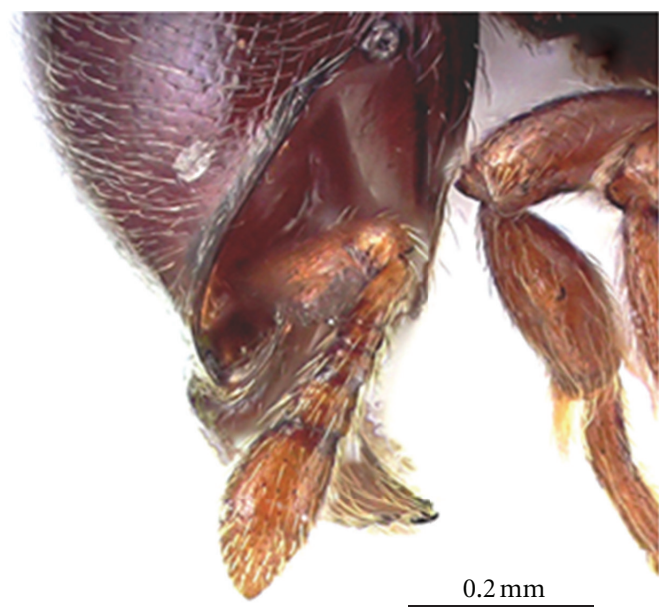

FIGURE 3: Tatuidris kapasi: holotype worker. Detail of head: left side view.

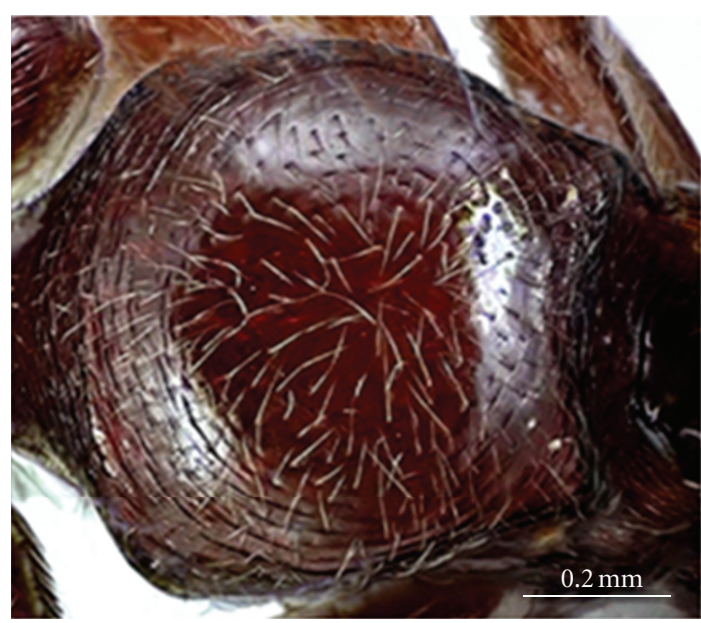

FIgure 4: Tatuidris kapasi: holotype worker. Mesosoma: dorsal view.

the following characters (states for T. tatusia indicated in brackets): occipital border a little more concave (nearly straight); about 5-6 facets in each eye (about 10 facets); clypeus with the free margin medially straight and laterally concave (free margin concave overall); pronotum with the ventral sector of lateral faces smooth and shining (with longitudinal rugulae); dorsum of mesosoma mostly sculptured with concentric rugulae and carinulae (mostly smooth and shining); mesosoma as seen from above with lateral margins moderately converging backward (Propodeum width/Pronotum width $=0.55$ ) (lateral margins more converging backward (Propodeum width/Pronotum width = $0.45)$ ); mesopleuron with anterior crest wider and ventrally truncated (crest narrower and not truncated); mesopleuron smooth and shining, except for punctuations and areolae on its ventral margin (with longitudinal rugulae and areolations); metapleuron punctate and areolate, and with longitudinal rugulae around the metapleural gland orifice (metapleuron with areolations); the bulla of the metapleural gland (visible through the integument when observed in profile), forming a ring whose posterodorsal margin is fused with the posterolateral margin of the propodeum (the bulla of the metapleural gland forming a ring that is distinctly separated from the posterolateral margin of propodeum); propodeal declivity less concave in lateral view (more concave); propodeal spiracle separated from declivitous margin of propodeum by two diameters (separated by no more than one diameter); viewed dorsally, petiolar node twice as wide as long (viewed dorsally, shape of petiolar node subrectangular, the node no more than about 1.5 times as wide as long); viewed dorsally, shape of postpetiolar node rectangular, and not wider behind than in front (viewed dorsally, shape of postpetiolar node subrectangular, and a little wider behind than in front); and dorsum of the petiolar and postpetiolar nodes with superficial concentric rugulae and carinulae (smooth and shining). Moreover, the pilosity is markedly more dense all over the body (more scattered) and does not include any long suberect setae (long suberect setae present). 


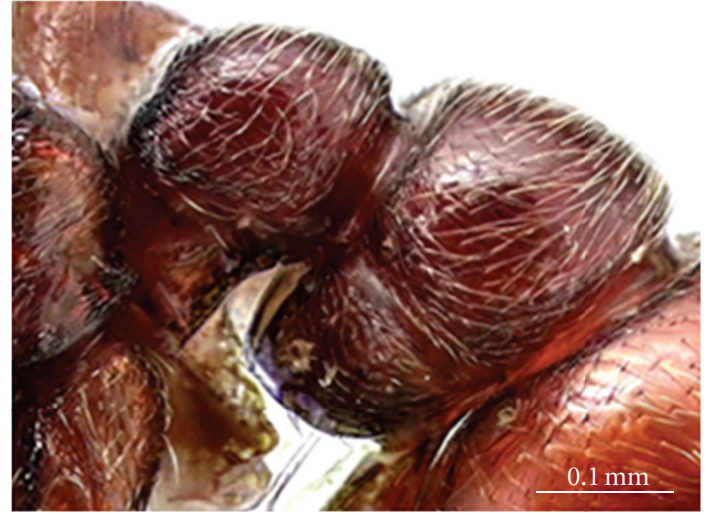

FIgURE 5: Tatuidris kapasi, holotype worker. Detail of petiole and postpetiole, left lateral view.

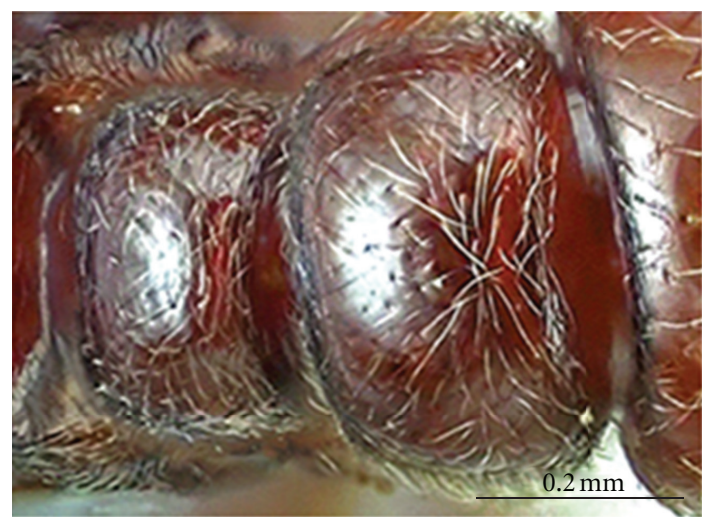

Figure 6: Tatuidris kapasi, holotype worker. Detail of petiole and postpetiole, dorsal view.

Furthermore, despite the fact that T. kapasi is known only by a single specimen and T. tatusia by two specimens formally described, the following comparative measurements suggest an overall size differential between the two species: the head shape is a little wider in T. kapasi (CI: 125,78) than in T. tatusia (CI: 118,2 \pm 1.56 , min-max: 117.07-119.28 $(n=2)$ ), the scape is slightly shorter in T. kapasi (SL 0,32 ) than in T. tatusia (SL 0,4 $(n=1)$ ), the pronotum is narrower in T. kapasi (PrW 0,64) than in T. tatusia (PrW 0,79 $(n=1))$, and the shape of the petiole node in dorsal view is more noticeably rectangular in T. kapasi (PeNI 200) than in $T$. tatusia (PeNI $153.64(n=1))$.

\section{Description}

Worker. Measurements (Holotype): TL 3.42, CI 125.80, EL 0.05, GL 1.00, HFL 0.50, HL 0.70, HW 0.93, LA7 0.27, ML 0.39, PeL 0.21, PeNI 200, PeNL 0.18, PeNW 0.36, PpL 0.28, PpNL 0.25, PpNW 0.45, PrW 0.64, SL 0.32, WL 0.80.

Except for the diagnostic characters, the external morphology of Tatusia kapasi sp. nov. is very similar to that of $T$. tatusia. In our discussion, the shared characters are regarded by ourselves as sufficient for the two species to be placed within the same genus. The spatial distribution and patterns of the sculpture and pilosity as well as the body color of this new species are described hereafter.

Sculpture. It includes head dorsum wholly smooth and shining, except for occipital sector covered with transverse carinulae; outer surface of mandibles smooth and shining except for longitudinal superficial striae on ventral (external) margin; ventrolateral sector of the head longitudinally carinulate; antennal scape shagreened and superficially areolate; pronotum ventrolaterally smooth and shining; dorsum of mesosoma with concentric rugulae and carinulae; mesopleuron smooth and shining except for punctuations and areolae on ventral margin; metapleuron with punctuations and areolae and longitudinal rugulae around the metapleural gland orifice; propodeal declivity mostly smooth and shining with fine striae and reticulate; petiolar and postpetiolar nodes laterally finely longitudinally carinulate.

Pilosity. It includes dorsum of head, mesosoma, petiole, and postpetiole with abundant setae, all fine, flexuous, and decumbent, varying in size and distribution as follows: some very short and relatively dense (i.e., those on clypeus and the outer surface of mandibles); others short and dense (those on dorsum of head, clypeus, mesosoma, petiolar, and postpetiolar nodes, and gaster); and others intermediate and dense (namely, setae on dorsum of head, mesosoma, petiolar, and postpetiolar nodes, dorsum of gaster and tibia). No long setae present.

Color. Body brownish-ferruginous, thick margins often appearing more blackish; legs brownish-yellowish.

Gyne and Male. They are unknown.

Geographic Range. This new species is known only from the type locality in French Guiana, situated at $260 \mathrm{~m}$ altitude in the Kaw Mountains, on a side exposed to the trade winds, near a great cave sheltering a big bat community. The local vegetation is typical of Amazonian lowland rainforest that is never flooded. New records of this species will probably occur in other localities of the Guiana Shield in the near future. However, the fact that no other specimen of Tatuidris has been recorded yet in the recent studies on ant biodiversity in the Guiana Shield, even using Winkler traps or other methods at a large scale $[18,19]$, suggests that this genus is genuinely rare in the Guianas, its members possibly spatially separated in small, isolated populations.

Biology. The biology of this species is unknown, but the fact that the type specimen was found in a leaf-litter sample, using a Winkler trap, suggests that it nests in some microhabitats of the leaf-litter or more or less deeply in the soil. It is also noteworthy that the leaf-litter sample (surface of $1 \mathrm{~m}^{2}$ ) in which $T$. kapasi was caught was characterized by a very high specific richness: a total of 20 other ant species belonging to 12 genera was recorded (Groc et al., unpublished information). Such richness in a unique leaflitter sample is uncommon in Neotropical forests [19]. 


\section{Comments and Discussion}

The description of this new species of Tatuidris is an important event for Myrmecology, since the genus has remained monotypic for over 40 years. However, as noted by Longino [4], the advent of litter sifting and Winkler extraction as a popular method of ant collecting in the last decade led to the discovery of new species belonging to genera previously considered as rare and poorly diversified. This is the case for the new species here described. This genus has been revealed to be not as rare as it was believed to be since several new specimens were recently collected in various Neotropical countries: Brazil, Colombia, Costa Rica, El Salvador, Ecuador, French Guiana, Mexico, Nicaragua, Panama, and Peru (see specimens imaged on the Websites: Ants of Costa Rica [4] and AntWeb [17]). In this context, D. Donoso is currently performing a first revision of this genus based on the new material deposited in myrmecological collections in the world.

While T. kapasi exhibits a distinct morphology from that of T. tatusia, it possesses all the diagnostic characters of Agroecomyrmecinae and Agroecomyrmecini. The next step will consist in studying the whole biology of these ants for which literature is particularly scarce. Tatuidris kapasi has peculiar mandibular brushes and a powerful elongated sting similar to that of T. tatusia. Brown and Kempf suggested that such adaptations indicates that armadillo ants might be specialist predators of active or slippery arthropod prey [3]. Also, we note that the flat pencil of stiff, curved yellow setae borne at the extensor angle on the forelegs, an apomorphy of this genus, may be used by these ants in order to clean the massive brush of heavy setae present along the inner surface near the masticatory margin of the mandible, through a movement directed forward. Thus, these characters could potentially represent an adaptation to feed on prey bearing a defensive pilosity. Moreover, the morphology of the gyne and the male of Tatuidris has never been described. However, microphotographs of a gyne and a male, together winged, are offered in the site Antweb, suggesting that a normal sexual reproduction by swarming occurs in this genus.

\section{Acknowledgments}

The authors thank Dr. Brian Heterick for his kind help in reviewing the English of this manuscript, and Bruno Corbara and Olivier Roux for field assistance. Financial support for this study was provided by (1) the Programme Amazonie II of the French CNRS (project 2ID), (2) the Programme Convergence 2007-2013, Region Guyane from the European Community (project DEGA), (3) the FPVI European-funded Integrated Infrastructure Initiative Grant SYNTHESYS (S. Groc), (4) the PRONEX Program FAPESB/ CNPq (PNX0011/2009, Brazil), and (5) the Program CAPES/ CNPq/MCT (PROTAX 52/2010, Brazil). J. H. C. Delabie acknowledges his research grant from CNPq. In accordance with Section 8.6 of the ICZN's International Code of Zoological Nomenclature, printed copies of the edition of Psyche containing this article are deposited at the following six publicly accessible libraries: Green Library (Stanford University),
Bayerische Staatsbibliothek, Library-ECORC (Agriculture \& Agri-Food Canada), Library_-Bibliotheek (Royal Belgium Institute of Natural Sciences), Koebenhavns Universitetsbibliotek, University of Hawaii Library.

\section{References}

[1] P. S. Ward, "Phylogeny, classification, and species-level taxonomy of ants (Hymenoptera: Formicidae)," Zootaxa, no. 1668, pp. 549-563, 2007.

[2] P. S. Ward, "Integrating molecular phylogenetic results into ant taxonomy (Hymenoptera: Formicidae)," Myrmecological News, vol. 15, pp. 21-29, 2011.

[3] W. L. Brown Jr. and W. W. Kempf, "Tatuidris, a remarkable new genus of Formicidae (Hymenoptera)," Psyche, vol. 74, pp. 183-190, 1968.

[4] J. T. Longino, “Ants of Costa Rica," 2011, http://academic.evergreen.edu/projects/ants/AntsofCostaRica.html.

[5] B. Bolton, "Synopsis and classification of Formicidae," Memoirs of the American Entomological Institute, vol. 71, p. 370, 2003.

[6] C. Baroni-Urbani and M. L. de Andrade, "The ant tribe Dacetini: Limits and constituent genera, with descriptions of new species," Annali del Museo Civico di Storia Naturale Giacomo Doria, vol. 99, pp. 1-191, 2007.

[7] B. Bolton and G. D. Alpert, "Barry Bolton's Synopsis of the Formicidae and Catalogue of Ants of the World, Version 3 January 2011," http://gap.entclub.org/.

[8] B. Bolton and G. D. Alpert, "Barry Bolton's Synopsis of the Formicidae and Catalogue of Ants of the World, Version 1 July 2011," http://gap.entclub.org/.

[9] R. A. Keller, "A phylogenetic analysis of ant morphology (Hymenoptera: Formicidae) with special reference to the poneromorph subfamilies," Bulletin of the American Museum of Natural History, vol. 355, pp. 1-90, 2011.

[10] S. G. Brady, T. R. Schultz, B. L. Fisher, and P. S. Ward, "Evaluating alternative hypotheses for the early evolution and diversification of ants," Proceedings of the National Academy of Sciences of the United States of America, vol. 103, no. 48, pp. 18172-18177, 2006.

[11] C. S. Moreau, C. D. Bell, R. Vila, S. B. Archibald, and N. E. Pierce, "Phylogeny of the ants: diversification in the age of angiosperms," Science, vol. 312, no. 5770, pp. 101-104, 2006.

[12] C. Rabeling, J. M. Brown, and M. Verhaagh, "Newly discovered sister lineage sheds light on early ant evolution," Proceedings of the National Academy of Sciences of the United States of America, vol. 105, no. 39, pp. 14913-14917, 2008.

[13] B. Bolton, Identification Guide to the Ant Genera of the World, Harvard University Press, Cambridge, Mass, USA, 1994.

[14] R. D. Eady, "Some illustrations of microsculpture in the Hymenoptera," Proceedings of the Royal Entomological Society of London, vol. 43, pp. 66-72, 1968.

[15] R. A. Harris, "A glossary of surface sculpturing," Occasional Papers on Systematic Entomology, vol. 28, pp. 1-31, 1979.

[16] C. R. F. Brandão, "Major regional and type collections of ants (Formicidae) of the world and sources for the identification of ant species," in Ants: Standard Methods for Measuring and Monitoring Biodiversity, D. Agosti, J. D. Majer, L. E. Alonso, and T. R. Schultz, Eds., pp. 172-185, Smithsonian Institution Press, Washington, DC, USA, 2000.

[17] B. L. Fisher, "AntWeb," 2011, http://www.antweb.org/descrip tion.do?Subfamily=agroecomyrmecinae\&genus=tatuidris\& name $=$ tatusia\&rank=species\&project $=$ worldants. 
[18] J. S. Lapolla, T. Suman, J. Sosa-Calvo, and T. R. Schultz, "Leaf litter ant diversity in Guyana," Biodiversity and Conservation, vol. 16, no. 2, pp. 491-510, 2007.

[19] H. L. Vasconcelos and J. H. C. Delabie, "Ground ant communities from central Amazonia forest fragments," in Sampling Ground-Dwelling Ants: Case Studies from the World's Rain Forests, D. Agosti, J. D. Majer, L.T. Alonso, and T. Schultz, Eds., vol. 18, pp. 59-70, Curtin University, Perth, Australia, 2000, School of Environmental Biology Bulletin, no. 18. 

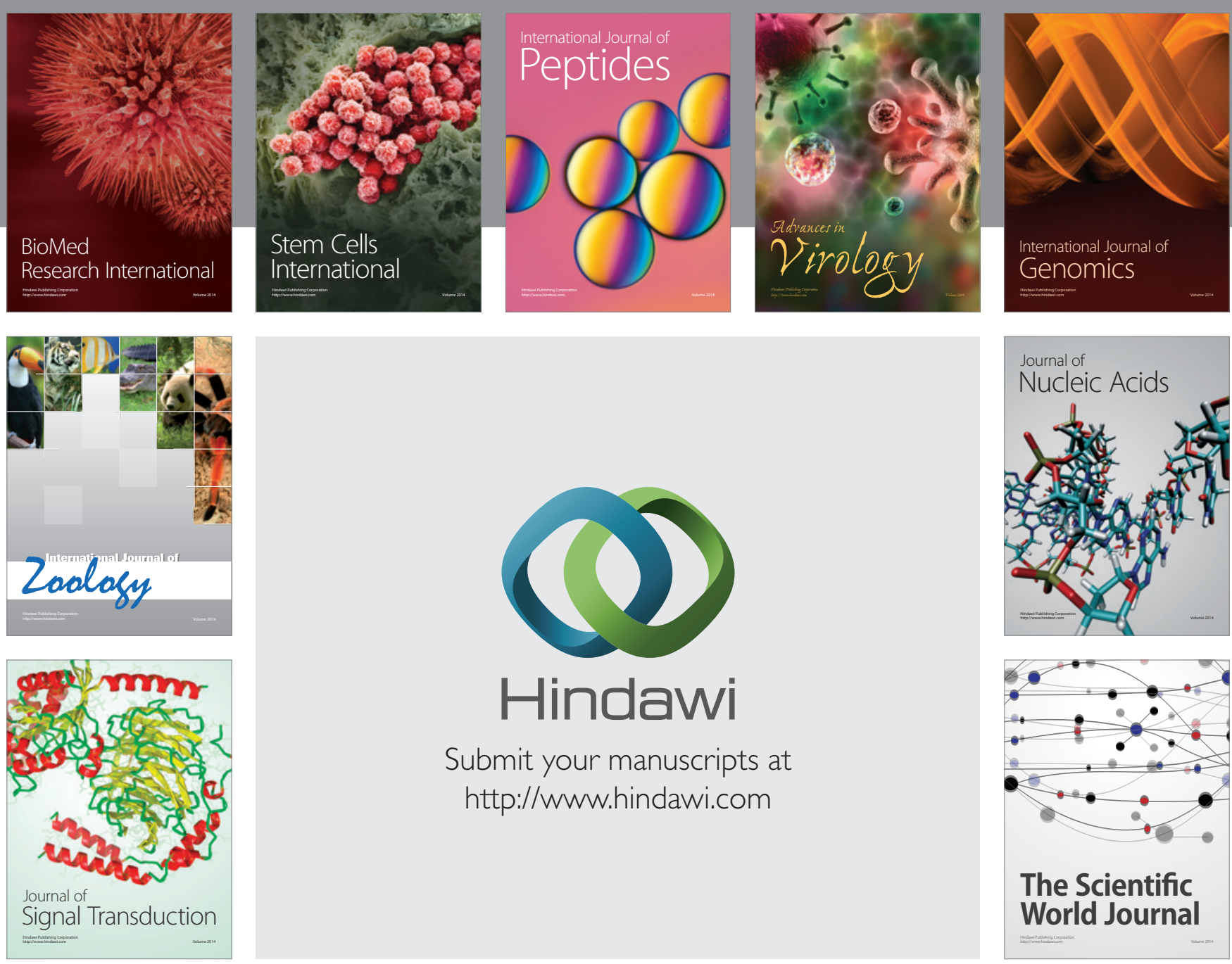

Submit your manuscripts at

http://www.hindawi.com
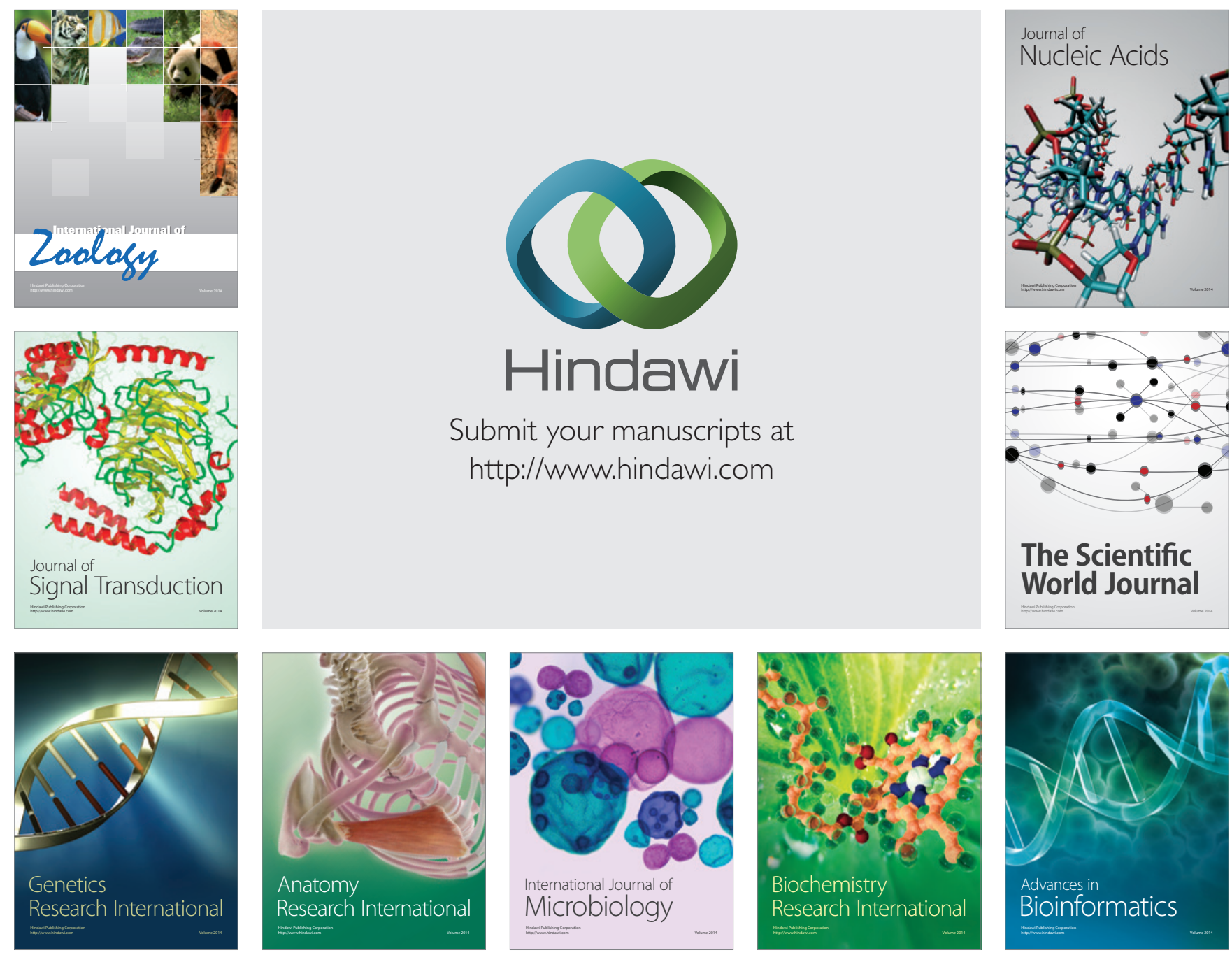

The Scientific World Journal
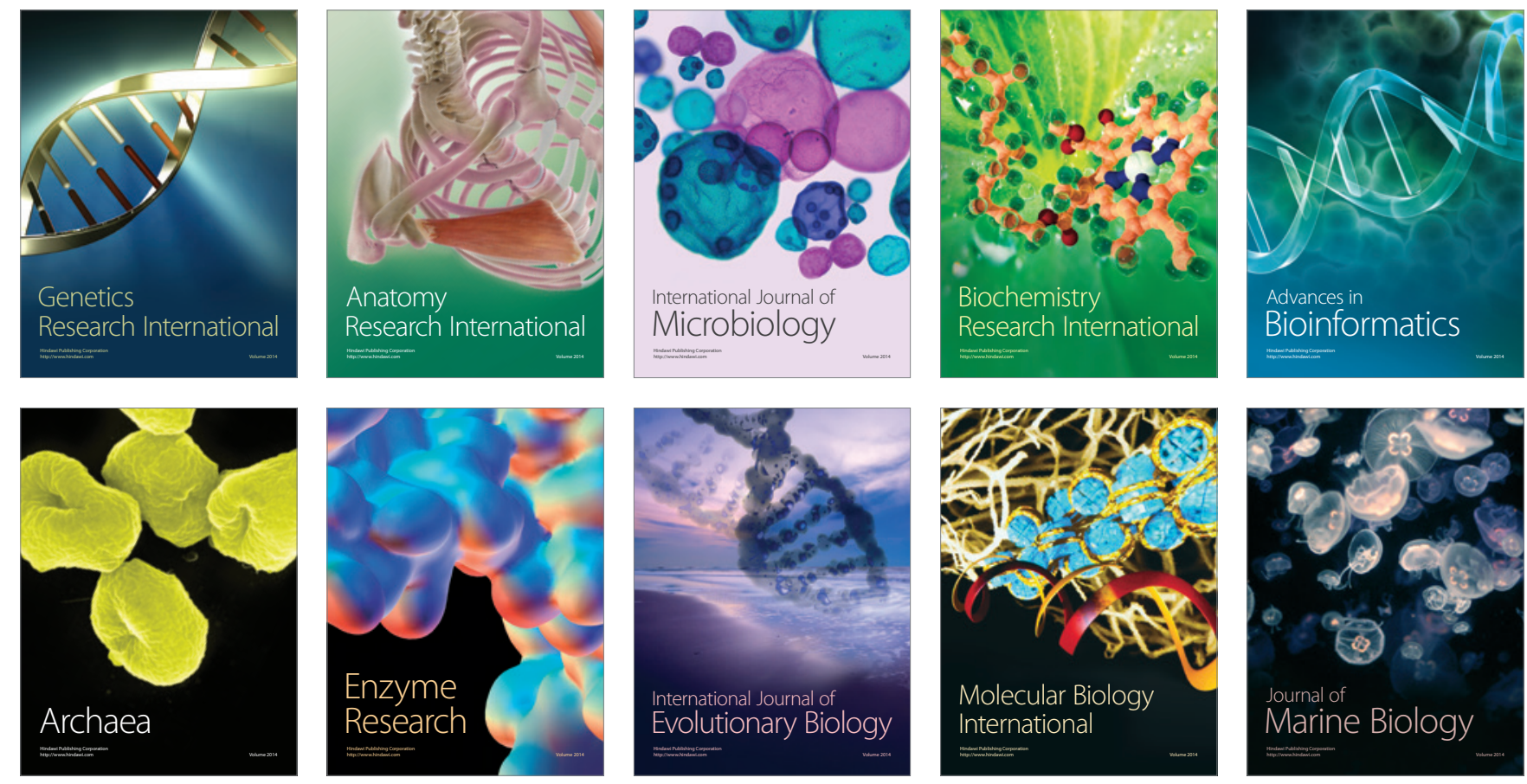